\title{
Towards an Aesthetic Space: A Comparative Study
}

\author{
Jonathan Reid
}

\begin{abstract}
This article aims to explore, through a literature review, what may be termed the aesthetic space' and to draw comparison with dialogical theories. The word 'aesthetic' literally means to take in the world through the senses. The study is based on theories and related principles from the fields of education, philosophy and psychology and from those of the world of the creative arts in determining what is meant by 'the aesthetic space'. Simultaneously, comparison is drawn towards an aesthetic approach to communication and dialogical theory. To enter the 'aesthetic space' is to engage creatively with the senses and the process of meaning making.

Besides a literature description, the study examines, through focus groups, questionnaires and video-analysis tasks, the I-positions of two groups of professionals (support and art workers) in analysing communicative agency in a deafblind/non-deafblind dyad engaging in an 'aesthetic space encounter'. Creative approaches are recommended for people with deafblindness and their social partners to develop agency within communication in the deafblind field.
\end{abstract}

\section{Keywords}

Communication, Aesthetics, Dialogicality, Intersubjectivity, Communicative Agency, Creativity, I-positions. 


\section{Introduction}

The word 'aesthetic' has been hijacked in recent years. The term, derived from the Greek 'aisthetikos', carries a certain semantic cargo, infused with the world of the temporal arts, of vistas, sunsets and, occasionally, even home décor. One may imagine commenting upon the 'aesthetics' of a painting, or a new car, or the colour of the grey sky against an angry sea... In fact, the word has its etymology rooted within the human sensori-neural system and literally means to take in the world through the senses. This rather embodied description is housed in the perception of the senses and although modern connotations can be concerned with the visual appreciation of art, for example, the definition of the word still pre-supposes an emotional reaction through the senses to a perceived stimulus. Nevertheless, within modern usage, it would be rare to describe a piece of music, or the feeling of the sun on one's back, or even the smell of baking bread as aesthetically pleasing. This article will travel towards a broader understanding of what may be termed 'the aesthetic space', within deafblind communicative practice and look to explore the links between dialogical theories and the aesthetic space. In doing so we will consider the role of the other within a deafblind/nondeafblind dyad and suggest the case for a widening of the I-positions adopted by social partners within communicative episodes.

\section{The Aesthetic Perspective}

In order to unpack what is meant by the "aesthetic space" we may turn first to the views of Augusto Boal, the Brazilian dramaturge, scholar, author and long-term friend of educator and philosopher Paulo Friere. Boal developed a global practice of using theatre to overcome oppression with marginalized groups. He maintains that the concept of "theatre" comes into existence when "the human being discovers that it can observe itself" (Boal, 1995, p.13). He is highlighting here a state of both subjectivity and objectivity which, he argues, is a fundamental human trait and ability. "A bird will sing but knows nothing of music. Singing forms part of their animal activity along with eating, drinking, coupling - and the song never varies. A nightingale will never sing like a lark. But the human being is capable of singing and seeing itself in the act of singing. This is why we can imitate, discover variations and compose." (Boal, 1995, p.14). For Boal, the aesthetic space is not concerned with physical surroundings but rather a state of improvisational flux, in which the protagonist can not only conceive of himself in relation to others, but has the ability to, through his actions, alter the dynamic of the world surrounding him.

Boal drives at this concept throughout much of his work and maintains that "theatre has nothing to do with buildings or other constructions. Theatre... is this capacity, this human 
property which allows man to observe himself in action, in activity." (Boal, 1995, pg.13). He differentiates between the profession of acting and the existence of 'the theatrical vocation' which belongs to all. He defines the aesthetic space as having a counterbalance between action and observation allowing the individual to "...observe itself, the human being perceives where it is and where it is not and imagines where it could go. A triad comes into being. The observing-I, the I-in-situ, and the not-I, that is, the other." (ibid.).

This rather wide-ranging statement can be supported by Hermans (2013) in describing the dialogical self and I-positions, which are "involved in processes of mutual dialogical relationships that are intensely interwoven with external dialogical relationships." (Hermans, 2013, p. 2). He continues; "The I fluctuates among different and even opposed positions, and has the capacity to imaginatively endow each position with a voice so that dialogical relations between positions can develop. The voices behave like interacting characters in a story, involved in a process of question and answer, agreement and disagreement." (ibid). Boal's aesthetic space, then, is both a physical space in which action and observation occur but also a psychosocial space in which potential I-positions can be affirmed and explored. For Boal, the aesthetic space is deeply intersubjective and full of potential for a myriad of I-positions to be adopted. He highlights the ability of the human mind to develop internal and external dialogues and to explore these positions in relation to the context in which the 'protagonist' finds himself. (Boal, 1979; 1995; 1999)

Boal's 'aesthetic space' ultimately considers, as its basis, a dialogical framework. This framework is indeed echoed throughout literature concerned with the temporal arts. The director and author Peter Brook in his exploration of the process of theatre, "The Empty Space', nods to Boal's definition of theatre as an innately held and intersubjective construct between two minds: "I can take any empty space and call it a bare stage. A man walks across this empty space whilst someone else is watching him, and this is all that is needed for an act of theatre to be engaged." (Brook, 1968, p. 2). In referring to the observer - the one who 'watches', and the symbiotic relationship with the protagonist, - the one who 'does', Brook explains the process in which theatre is born and takes us a step further towards the ubiquitous nature of creative engagement within a dialogical landscape. For Brook also, theatre is not concerned simply with the dialogue spoken between characters, but the dialogue between observing audience and active performer. Moreover, he is concerned with the inner dialogue as a process both of the actor and of the spectator.

For Brook and Boal then, theatre, in this sense, is a metaphor for communication. It occurs between two minds and can be altered, negotiated over and observed by both. The dialogical nature of this 'communion' is celebrated at a societal level across the world within artgalleries, theatres, nightclubs and even churches, but for Boal the alchemy of the aesthetic space is aligned within the ego-alter positioning of the dialogic self in relation to the other. In his work Boal recognised the concept of the "dynamic multiplicity of I-positions in the 
landscape of the mind" (Hermans, 2013, p. 2), writing: "I see and I see myself, I speak and I listen to myself, I think and I think about myself; all of which is only possible because of the doubling of the 'I': I-now' perceives 'I-before' and has a presentiment of (anticipates) a 'possible-I', a 'future-I'”' (Boal, 1995, p. 28).

If we turn next to Ellen Dissanayake, we may begin to develop a wider understanding of aesthetics and, indeed, the arts. "The arts - ours and those of others - are ways of treating the inner life seriously, embodiments of our affective experience" (Dissanayake, 2000, p. 192). Dissanayake also helps to move our focus away from the archetypal standpoint of experiencing art as a concept which is made by artists and highlights what can perhaps be considered as that most human and innate of aesthetic experiences; that of a pre-linguistic child and mother. "Baby talk... has nothing to do with the exchange of verbal information about the world and everything to do with participating in an impromptu expression of accord and a narrative of feelings, ideas, and impulses to act." (Dissanayake, 2000, p. 45). She is describing a deeply intersubjective, declarative communicative episode in which two brains are coordinated in a state of attuned emotionality, praxis and possibility. This state can be described as "interactive togetherness" (Nafstad \& Rodbroe, 1999, p. 18) and highlights the co-creative properties of a partnership at a level which is as yet unconcerned with the imperative functionality of language, but enveloped within the semantic process and joy of sharing oneself with another.

Dissanayake develops upon her contention of an innate psychobiological aesthetic propensity within the human infant, highlighting that "the experience of the temporal arts of poetry, music and dance (the movements of which accord with music) inhere in our fundamental psychobiology - our inner brain sense of rhythm and melody." (Dissanayake, 2000, p. 38) This chimes with Malloch and Trevarthen's theory of 'communicative musicality' (2009) in which the musical components of 'pulse', 'quality' and 'narrative' are explored as an innate protolinguistic 'language' between mother and infant (and beyond) and conjecture that relationships that are emotionally charged with musical dance-like qualities are the foundation for all forms of communication. Johnson (2007), discusses the body as a conduit for deriving meaning from these early exchanges, writing: "We inhabit a shared world and we share meaning from the start, even if we are completely unaware of this while we are infants. In other words, bodily-based intersubjectivity - our being with others via bodily expression, gesture, imitation and interaction - is constitutive of our very identity from our earliest days, and it is the birthplace of meaning." (Johnson, 2007, p. 51).

This early interaction is, arguably, guided by aesthetic bio-psychosocial processes within the mind and body. Dissanayake asserts that humans are naturally drawn to 'the special', through Darwinian evolutionary conditioning and cultural manipulation. "In aesthetic experience, we not only notice and are attracted by naturally enticing and striking features that set apart an event or object from un-enticing or ordinary events or objects. Something 
additional is done to the qualities, events, or objects: they are additionally patterned and exaggerated or otherwise emphasised so that they become more colourful or vivid, complex or elaborate, harmonious or unified, compelling or moving than their non-aesthetic counterparts. I would say that when strikingness is deliberately added by intentional emphasis, the aesthetic enterprise begins." (Dissanayake, 2000, p. 212).

John Carey, the arts critic, author, professor of English literature at Oxford University and cultural iconoclast draws upon this point also, writing that; "Value... (in the arts), it seems evident, is not intrinsic in objects, but attributed to them by whoever is doing the valuing." (Carey, 2005, p. xiv). For Carey, the aesthetic process is also innate yet subjective. Within a dialogical framework however, we may see that the 'intentional emphasis attributed by whoever is doing the viewing' is part of a rich co-constructed and multitudinous process. An actor can only become a character through the process of an audience member observing him as such. An artwork only becomes a work of art when constructed as such and therefore validated by an observer. The aesthetic space is, by definition, dialogical. We may draw from this that an aesthetic space encounter may at times have an imperative nature but is infused with the declarative co-creative task of influencing the other's (I-Alter) "attentive state about some aspect of the world." (Souriau, Rødbroe \& Janssen, 2008, p. 38).

In exploring this within a communicative framework we may now draw on Nadel and Camaioni's statement that "...a communicative episode is 'an on-line process of adaptation to each other within which intentions and emotions are shared and negotiated." (Nadel \& Camaioni, 1993, p. 155). This concept draws our attention to the intersubjective dialogue that exists between partners and the process of dynamically sharing and co-creating communication together. (Rødbroe \& Janssen, 2006, p. 9).

Hart, (2002) considers the arts in relation to communication and gels together viewpoints gathered from Schön, Trevarthen and Sacks amongst others. He draws comparison between the inherent improvisational skill of jazz musicianship and the potential abilities within communicative partnerships in referencing Schön, who writes: "When good jazz musicians improvise together, they also manifest a 'feel for' their material and they make on-the-spot adjustments to the sounds they hear. Listening to one another and to themselves, they feel where the music is going and adjust their playing accordingly..." (Schön, 1983, p. 259). Latterly, this notion is supported by Zeedyk who states; "Most recently, parent-infant interactions have been likened to a jazz duet, given that the two partners are not dancing to someone else's tune but are creating one of their own." (Zeedyk, 2006, p. 2). This ability to improvise in action is described not simply as an acquired skill by Colwyn Trevarthen, rather he strikes a similar chord to that of Dissanayake, in pointing to this as an innate and intrinsic element of humanity. "...We have underestimated the poetic and musical awareness of young infants, and this points to the non-verbal abilities all humans must possess, and the kind of rhythmic and emotional machinery they must have in their heads, if they are to interact 
mentally and make sense of one another's feelings, actions, ideas and opinions." (Trevarthen, 1995, p. 92). Oliver Sacks develops this further; "What we see... is the power of music to organise - when abstract or schematic forms of organisation fail... Thus music, or any other form of narrative, is essential... And in drama there is still more... The capacity to perform, to play, to be, seems to be a 'given' in human life, in a way which has nothing to do with intellectual differences." (Sacks, 1985, p. 186).

The above theories and thinking point to the aesthetic space as being that which is concerned with not only the relational aspects of 'I' with the 'other' within a communicative context, but also a space of spontaneous agency, of elaboration and "making special" (Dissanayake, 2000). It is argued that the properties of this space are innate, at least the human ability to come into the world with a knowledge of the capacity to play and to influence others. The construction of an aesthetic space encounter also functions at the level of the partnership within a dialogical context. Within an aesthetic space encounter, the concept of intersubjectivity is fundamental to the process. For a communicative dyad to share a degree of success, both partners, by definition, must be able to experience each other and the environment at a kinaesthetic and emotional level which is concordant with each other. The aesthetic space requires both partners to observe themselves in the context of the dyad, and to have the agency to influence the narrative of this union in a multitude of expressive and joyful ways which can be shared, referred to and built upon by both.

\section{A Dialogical Perspective}

Let us turn now to Macmurray's thoughts:

"The unit of personal existence is not the individual but two persons in personal relation; and that we are persons not by individual right, but in virtue of our relation to one another...The unit of the personal is not the 'I' but the 'You and I'.'

(Macmurray, 1961, p. 18)

In examining what is meant by the above we may consider Linell's argument that "dialogicality is an attribute of human sense making, that is, the dynamic processes, actions and practices in which meanings are contextually constituted in the interactions of human beings with others and environments." (Linell, 2009 p. 30). Linell differentiates between the terms 'dialogue theory' and 'dialogism', dealing with the latter term as more "abstract, epistemological and (meta)-theoretical... applicable to human sense-making." (Linell, 2009, p. 7). In taking on this point we may distance ourselves from the construct of language within the epistemological common derivative of the word 'dialogue', and focus instead on the 
intersubjective meaning making properties of a communicative project. This is not to say that language, and the act of using language is not dialogical, rather that for Linell, dialogicality is concerned with two minds meeting in space and over time and our "being in the world is thoroughly interdependent with the existence of others". (Linell, 2009, p. 7). Gergen develops a similar thread and writes; "Individuals, themselves, cannot 'mean' anything: their actions are nonsensical until co-ordinated with the actions of others. If I extend my hand and smile, the gesture hovers at the edge of absurdity until reciprocated by another." (Gergen, 1991, p. 242).

Dialogical theory outlines, then, that meaning comes into existence when two different 'selves' are in union. The dialogical self is held, always, in relation to the other within the human mind. "The limits of the self are not within the I, but within the relationship with the other, 'I and thou'. Every individual makes his/her world in terms of others by dialogically constructing and re-constructing the social world as a set of multifaceted and multi-voiced realities situated in culture." (Markova, 2007, p. 8). In describing this notion of the "I-alter" process we can draw a direct link back to Boal's contention that "theatre comes into existence when man discovers that he can see himself". The fundamental process of an internal dialogue in which the "I" can address and compare a multitude of alternate positions and in doing so generate meaning, or, perhaps, impose meaning upon the world.

Linell suggests dialogism, as opposed to monologism, as a prevailing theory for biopsychosocial development in the human mind. "When we 'construct' the world, it is a question of intersubjective co-construction with the help of others and artifacts (sic). It is also a partial construction in the sense that the world itself provides the material for construction." (Linell, 2009, p. 19) For Linell, dialogue is something 'possessed' by the participants, or by the Ipositions of the inner I-alter relationship, and therefore 'meaning' is constructed through a process of mutually coordinated interactions, or 'mediations' with the other. Each action, within this intra and inter-dialogue, builds upon and draws significance from past sequential experiences, contextualising and appropriating meaning in relation to the present. The dialogical relationship is embedded within a contextual framework, gathering meaning not just from the dyadic relationship with the other, for example, but also from the world surrounding this relationship. The co-authorship of dialogue between the 'I' and 'other' is therefore situated within and referent to the context, other-directed in nature and coconstructed sequentially in relation to the past. "For example, an utterance is always an 'utterance in context', and a speaker is a speaker-interacting-in-situ'." (Linell, 2009, p. 24).

A strong correlation of ideologies exists between the dialogical theories explored above and the aesthetic space of Boal. He describes the human mind as "tri-dimensional (the I who observes, the I-in-situ and the not-I)" (Boal, 1999, p. 14) and echoes Linell's dialogical principles, describing the aesthetic space as being "penta-dimensional" (Boal, 1999, p.16), that is, concerned with the relationship of I-other, situated within a shared context and guided 
by the memories of its inhabitants. Boal, however, develops the concept of imagination as a property of the aesthetic space. This can be construed as a process of amalgamation of the mind involving ideas, emotions, sensations and memory. Boal contends that "I cannot recall something without imagination, since memory itself forms part of the process of imagination" (Boal, 1999, p. 21). The ability to play, to improvise and to imagine where one could potentially be in relation to the other is both a dominant mainstay of the aesthetic space, and central to our understanding of dialogical theory.

In considering the above we may now draw links between the properties of the aesthetic space and those of perspectives pertaining towards dialogical theory and wider supporting concepts. 
Table 1

Table outlining Correlation between Aesthetic Space Perspective and Dialogical Theories

Aesthetic Space Perspective Dialogical Theories Perspective

A space in which one can observe oneself in action - and be observed by others

An intersubjective space, between two or more brains

A dialogical space, between two or more Ipositions (internal and external), in which dramatic conflict may occur

A space of potential and improvisation

To do with emotion - Declaritive Space

An evolving process of "adaptation" to the other

An innate "given" in human life

A space explored 'through the senses'

A space of imagination and creativity

A space of equal agency
"Ego-Alter-Other relationships" - Markova, I.

"...being in the world is thoroughly interdependent with the existence of others" Linell, $\mathrm{P}$.

"Dialogic Tension" - Bakhtin, M.

Ego-Alter Interdependence - Markova, I.

"...journeys where new worlds beckon" Zeedyk, S.

"Affective Attunement" - Bräten, S

...treating the inner life seriously.",

"...impromptu expression of accord and a narrative of feelings, ideas and impulses to act" - Dissanayake, E.

"A place to share the mind's ideas and interests with the other", Daelman, M.

"A dialogue is something participants possess, experience and do together" - Linell, $\mathrm{P}$

"a newborn infant is organised as a psychological subject at birth... seeking to enter into regulated engagements with...other human beings." Aitken, K. Trevarthen, C.

"Our inner brain sense of rhythm and melody." - Dissanayake, E.

"Bodily-based intersubjectivity" - Johnson, D.

Boal, A.

"a social process by which individuals dynamically alter their actions with respect to the ongoing and anticipated actions of their partners." Fogel, Trevarthen, Aitken "Joint construction" - Linell, P. 


\section{Co-construction of the other within the aesthetic space}

A recent thesis by the author (Reid, 2014) examines if the I-positions of a group of support workers in the deafblind field lead to a different construction of communicative agency within a deafblind/non-deafblind dyad as compared with a group of artist-workers in the deafblind field. An underlying hypothesis of this question is the notion that 'If I see myself in the role of 'support worker' do I see in front of me 'someone who needs support'? However, if I see myself as an artist or a musician, does this enable me to see another artist or musician in front of me, somebody who possesses the same creative, explorative properties as I?' The overarching question posed holds relevance for the development of declarative communication within the roles of professionals in the deafblind world and suggests wider implications for the expansion of approaches to co-creative communication within the field.

Hart (2008) considers the ideological change from the educational zeitgeist of the nineteen-sixties, seventies and eighties, which concerned itself with the acquisition of language as a primary goal within the deafblind field. He cites Rødbroe and Souriau in stating that "this is because the teaching methods used in the past relied too much on symbolic communicative systems, viewing communication primarily as a means of delivering messages, rather than as a means of people engaging emotionally and psychologically with one another... So one practical implication... is that communication partners need to prioritise declarative functions of language over imperative ones." (Hart, 2008, p.74). In exploring interaction within a deafblind/non-deafblind dyad, Nafstad and Rødbroe point towards declarative communication within an aesthetic realm: "Interacting means playing together. Interacting with deafblind individuals means using oneself as an instrument and improvising. It means composing themes for interaction and variations on themes and combinations of themes. It means varying or altering one's own musical dimensions in order, all the time, to dance the same dance as and with the deafblind individual, and letting him lead you. It means letting the deafblind individual choose the musical components (rhythmical movement patterns and vocal patterns) and letting him make the shifts of mood between major and minor. You must remain attuned to these emotional shifts." (Nafstad \& Rødbroe, 1999, p. 49).

The aesthetic space, as discussed, is both a metaphorical space which exists between two minds and a metaphysical space in which meaning is derived through the senses. It is a space of imagination and of emotion and perhaps most centrally it encourages states of improvisational flux and attunement to occur within the minds of its inhabitants. This article has drawn attention to the theories that underpin this space being, far from an acquired or learnt skill (such as those of an actor or dancer), but rather as a universal characterisation within the human mind. Therefore this aesthetic 'mind space' is held by all and realised, in 
varying degrees in relation to our I-positions in regard of the other. To enter the 'aesthetic space' is not only to be able to bestow a subjective value upon a stimulus such as viewing a piece of art or a sunset. It is to engage creatively with the senses and the process of meaning making. Johnson writes: "we need a philosophy that sees aesthetics as not just about art, beauty, and taste, but rather as about how human beings experience and make meaning. Aesthetics concerns all of the things that go into meaning - form, expression, communication, qualities, emotion, feeling, value, purpose, and more." (Johnson, 2007, p.212).

To travel towards the declarative, within our communicative exchanges with people with deafblindness brings us closer to the notion of 'I and thou' and moves our interactions away from an imperative matrix. This matrix may relegate both partners to an 'I-It' position by stifling the agency of the other within our relationships. Within his thesis "The Aesthetic Space: A Creative Route to Communicative Agency', Reid (2014) explores 'the aesthetic space', and in particular the influence of this upon working approaches with deafblind people.

The study considered two groups of professionals working within the deafblind field. One group comprised of support workers in the field and the second group comprised of arts workers. The support worker group can be said to have a non-aesthetic space perspective and the arts worker group can be said to have an aesthetic space perspective. A questionnaire was distributed to each group and gathered data on the participant's I-positions in relation to their job roles with deafblind people. There appears to be a marked contrast in how the two groups of professionals constructed their own role in relation to deafblind people. This, however, is in line with the job descriptions assigned to each professional position. The participants of both groups were then asked to watch a short film of a deafblind/non-deafblind dyad engaging in an aesthetic space activity (in this case a form of Contact Improvisation dance). Both groups were then asked to complete a task in which the following information was given:

- Broadly speaking there are two types of communication: Imperative and Declarative. Both are equally valid and important and both are needed in order to convey meaning and make sense of the world. Please study the definitions below:

- Imperative behaviour: Trying to obtain a change in the world, realised by the interaction partner who is seen as somebody with agency. That means who can do something for you. It is functional instrumental behaviour.

- Declarative behaviour: Trying to influence the mind of the other, who is not only seen as somebody with agency, but also as somebody who can share your ideas and interests. 
Participants were then asked to watch several short clips of a deafblind/non-deafblind aesthetic space encounter and assign either an 'imperative', 'declarative' or 'both' mark to each clip.

In analysing the data gathered from this task a contrast was observed in the separate group's construction of communicative agency within the filmed dyad. The support worker sub-group constructed the communicative agency of the partnership as 48\% Imperative, 31\% Declarative and 22\% Both. The arts worker sub-group constructed the communicative agency of the partnership as 6\% Imperative, 58\% Declarative and 36\% Both. There was a distinct trend within the responses of the support worker group to construct themselves within a functional, imperative role in their relationships. Answers concerned with "support", "safety" and "maintaining routines" were typical responses. In addition the responses of the questionnaire referred to disability or "vulnerability" within five of the eight participant's answers. In contrast, the arts workers responses showed a distinct trend towards a declarative role within their relationships. In this case typical answers concerned "communication, relationships and a sharing of creative expression". In addition the responses of the questionnaire referred to disability only once.

It is of equal interest, however, to note that the responses from the artist-workers rarely strayed into discussing the functionality of the artistic task. Within arts sessions there is still a need for imperative, functional behaviour. To provide a safe environment, to ensure access and adaptability of materials, to discuss what medium to work in today or which instrument to use next are all of high importance and, indeed, essential requirements for a successful arts session to occur. Similarly, the support workers rarely alluded to the emotional, creative roles that they undoubtedly inhabit within the relationships they form with deafblind people. Support based tasks such as accessing public transport, eating and drinking, getting out and about and following daily activity plans together hold the potential for a plethora of imaginative and aesthetic possibilities for both partners to inhabit and share. The act of making a cup of tea together, for example, can be seen as both an imperative functional process of sequences involving cups, teabags, hot water etc. and yet also has the potential to become a dramatic and musical aesthetic space encounter, full of tension, improvisation, crescendos of action, humour-laden novelty and mutually-achieved resolutions.

Within the latter experience, which we may now describe as an aesthetic space encounter, the ability to co-construct meaning and develop our potential for communicative agency within a deafblind/non-deafblind dyadic encounter is heightened declaratively according to Fogel et al (2002). Within the aesthetic space we may travel towards declarative communication and inhabit I-positions of 'fellow-travellers', which can be co-regulated and held within the prism of affective attunement at the level of the partnership. The aesthetic space, concerned with sensory communion over each other and the 'strikingness' of triadic 
elements creates a fertile environment for intersubjectivity to occur and promotes a coauthorial pathway towards declarative communication.

In exploring educational, social, philosophical and aesthetic theories within the study, and in particular, dialogical theory, we may conclude that the I-positions one holds in relation to the other have an impact upon the construction of the other's communicative agency. The 'third voice' within dialogical theory may manifest itself at a local, organizational level or a global sociological level and influence one's I-alter process to the extent that it impacts upon the I-thou paradigm. The writer maintains that in employing principles and concepts drawn from the aesthetic space within communicative exchanges with deafblind people, a natural widening of I-positions for the communication partner and therefore the deafblind person is possible. If 'I' can see herself as a creative, aesthetic being then 'You' can also be constructed as such. If the third voices that govern the roles within the dyad promote aesthetic potential in the other - as they have done since our earliest interactions with our parents - then we may move closer towards a declarative communion between 'I' and 'You'. In contemplating Markova's statement that third voices “...may be firmly established in society... and often function implicitly under the level of consciousness." (Markova, 2008, p.18) The writer concludes that the aesthetic space may offer up potential for deafblind people and their partners to hold these dialogical positions up to the light, for examination. 


\section{References}

Boal, A. (1979). Theatre of the Oppressed. London: Pluto Press.

Boal, A. (1992). Games For Actors and Non-Actors. London: Routledge.

Boal, A. (1995). The Rainbow of Desire: The Boal Method of Theatre and

Therapy. London: Routledge.

Brook, P. (1968). The Empty Space. New York: Touchstone Simon \& Schuster Inc.

Carey, J. (2005). What good are the arts? London: Faber and Faber Ltd.

Dissanayake, E. (2000). Art and Intimacy: How the arts began. Seattle: University of Washington press.

Fogel, A., de Koyer, I. (2002). The Dialogical Self in the First Two Years of Life: Embarking on a Journey of Discovery. Theory \& Psychology, Volume 12, 191-205.

Gergen, K.J., (1991). The saturated self: Dilemmas of identity in contemporary life. New York: Basic Books.

Hart, P. (2002). My head is alive - a prelude to self determination in A minor by J.S. Bach. Presentation delivered at Sense Scotland conference 7.9.2002.

Hart, P. (2008). Sharing Communicative Landscapes with Congenitally Deafblind People: It's a walk in the Park! In S. Zeedyk (Ed.), Promoting Social Interaction for Individuals with Communicative Impairments: Making Contact (pp. 66-83). London: Jessica Kingsley Publishers.

Hermans, H. (2013). The Dialogical Self. Deafblind International Conference Proceedings, Lille. (pending publication).

Johnson, M. (2007). The meaning of the body - Aesthetics of human understanding. London: The University of Chicago Press.

Linell, P. (2009). Rethinking language, mind and world dialogically. Rijksuniversiteit Groningen: Information age publishing.

Macmurray, J. (1961). Persons in relation. London: Faber and Faber.

Malloch, S. Trevarthen, C. (2009). Communicative musicality. Oxford: Oxford University Press. Markova, I. (2008) Dialogicality. Presentation at DbI Communication Network conference Cocreating Communication with Persons with Congenital Deafblindness, October 8-11 2008, Leeds, UK. (Available as download www.sense.org.uk).

Markova, I., Linell, P., Grossen, M., \& Salazar Orvig, A. (2007). Dialogue in focus groups. Exploring socially shared knowledge. London \& Oakville: Equinox.

Nadel, J., Camaioni, L. (1993). New perspectives in early communicative development. London: Routledge.

Nafstad, A., Rodbroe, I. (1999). Co-creating Communication. Denmark: Forlaget Nord-Press.

Reid, J. (2014) The Aesthetic Space: A creative route to communicative agency. (unpublished thesis) The University of Groningen.

Rødbroe I., Janssen, M. (2006). Communication and congenital deafblindness I. Congenital deafblindness and the core principles of Intervention. Sint-Michielsgestel: VCDBF/Vitaal.

Schön , D. (1983) The Reflective Practitioner: How professionals think in action. London: Basic Books.

Sacks, O. (1985) The Man Who Mistook His Wife for a Hat. London: Macmillan. 
Souriau, J., Rødboe, I., Janssen, M. (Eds.). (2008). Communication and Congenital Deafblindness III. Meaning Making, Sint-Michielsgestel: VCDBF/Vitaal.

Trevarthen, C. (1995). The child's need to learn a culture. Children and Society, Volume 9: Issue 1, 5-19.

Zeedyk, M.S. (2006). From subjectivity to intersubjectivity: the transformative roles of emotional intimacy and imitation. Infant and Child Development, 15: 321-44

Jonathan Reid, MSc., Creative Arts Tutor,, Sense Scotland, Touchbase, 43 Middlesex Street, Glasgow, Scotland; e-mail:< jrreid@sensescotland.org.uk>. 